\title{
Is bicarbonate directly used as substrate to participate in photosynthetic oxygen evolution
}

\author{
Yanyou $\mathrm{Wu}^{1}$
}

Received: 4 June 2021/Revised: 4 June 2021 / Accepted: 8 June 2021 / Published online: 21 June 2021

(C) The Author(s) 2021

\begin{abstract}
If the photosynthetic organisms assimilated only $\mathrm{CO}_{2}$ in the Archean atmosphere, hydroxide ion in the Archean seawater would not increase. If plants would not consume bicarbonate as a direct substrate during photosynthesis, it is difficult to explain the evolution of Earth's environment. To date, it is generally accepted that photosynthetic $\mathrm{O}_{2}$ evolution of plants come from water photolysis. However, it should be debated by evaluating the effect of bicarbonate in photosynthetic $\mathrm{O}_{2}$ evolution, analyzing the role of carbonic anhydrase (CA) in photosynthetic $\mathrm{O}_{2}$ evolution, and the relationship between thylakoid CA and photosynthetic $\mathrm{O}_{2}$ evolution. In the paper, I propose that bicarbonate is directly used as substrate to participate in photosynthetic $\mathrm{O}_{2}$ evolution. The rationality of bicarbonate photolysis of plants is discussed from the thermodynamics and evolution of Earth's environment. The isotopic evidence that bicarbonate is not the direct substrate of photosynthetic $\mathrm{O}_{2}$ release is reexamined, and the new explanation of bicarbonate photolysis in photosynthetic $\mathrm{O}_{2}$ evolution is proposed.
\end{abstract}

Keywords Bicarbonate photolysis - Carbonic anhydrase . Photosystem II · Photosynthesis · Water photolysis

Yanyou Wu

wuyanyou@mail.gyig.ac.cn

1 State Key Laboratory of Environmental Geochemistry, Institute of Geochemistry, Chinese Academy of Sciences, 550081 Guiyang, People's Republic of China

\section{Seemingly final verdict}

Carbon dioxide as the substrate of photosynthesis has been generally accepted, but bicarbonate as the substrate of photosynthesis has been controversial. At present, the role of bicarbonate in photosynthesis and oxygen evolution is specious, even contradictory. Some researchers believe that bicarbonate can stimulate the oxygen release of plants, which depends on either the acceptor side of Photosystem II (Van Rensen \& Xu 1999; Van Rensen 2002) or the donor side of Photosystem II to stable $\mathrm{O}_{2}$ evolving complex(Klimov et al. 1995a,b; Baranov et al. 2000). However, some researchers argue that bicarbonate play a direct role in oxygen evolution of plants (Stemler 1980, 2002), or no evidence provide for that it coupled and bound in the $\mathrm{O}_{2}$ evolving complex of Photosystem II (Clausen et al. 2005; Aoyama et al. 2008; Shevela et al. 2008; Ulas et al. 2008). Meanwhile, some isotopic evidence presents that bicarbonate does not work as a direct substrate in photosynthesis (Stemler \& Radmer 1975; Metzner et al. 1979; Radmer \& Ollinger 1980; Clausen et al. 2005), which makes the majority of people reach a consensus that oxygen released by plants must come from water in photosynthesis.

\section{Bicarbonate effect in photosynthetic $\mathrm{O}_{2}$ evolution}

In 1958, Otto Warburg and Günter Krippahl firstly discovered that bicarbonate can stimulate the Chlorella release oxygen under the action of artificial reductant (Warburg \& Krippahl 1958). In the following 60 years, many scientists studied the "bicarbonate effect" from different aspects of photosynthetic $\mathrm{O}_{2}$ evolution, and got their own views and opinions, which are obtained from different 
works on different research materials under different conditions by using different means and methods.

\section{Effect of bicarbonate on both the acceptor and the donor side of Photosystem II}

The first evidence for an effect of bicarbonate on the acceptor side of Photosystem II was provided by Wydrzynski and Govindjee (1975), who measured chlorophyll $a$ fluorescence induction kinetics in spinach chloroplasts after $\mathrm{CO}_{2}$ depletion in the presence of various artificial electron donors. They found that the variable fluorescence yield measured as a function of decreasing bicarbonate concentrations are qualitatively similar to those observed with increasing concentrations of 3-(3,4dichlorophenyl)-1,1-dimethylurea (DCMU) which is known to block the reducing side in Photosystem II (Wydrzynski \& Govindjee 1975). Afterwards, Govindjee et al. (1976) found that the chlorophyll $a$ fluorescence decayed after the third flash in bicarbonate-depleted chloroplasts, and the decay was faster in the chloroplasts to which bicarbonate was added (Govindjee et al. 1976).

In 1977, Fred Crane and Rita Barr found that bicarbonate inhibited the DCMU-insensitive silicomolybdate reduction by Photosystem II but stimulated the $\mathrm{O}_{2}$ evolution associated with ferricyanide reduction in presence of dibromothymoquinone (DBMIB) (Crane \& Barr 1977). Paul Jursinic and Alan Stemler (1986) found that the photosynthetic electron flow between $\mathrm{Q}_{\mathrm{A}}$ (the primary quinone acceptors) and $\mathrm{Q}_{\mathrm{B}}$ (the secondary quinone acceptors) and $\mathrm{Q}_{\mathrm{B}}$ and the plastoquinone pool was the slowest when formate is bound, but the highest when bicarbonate is bound (Jursinic \& Stemler 1986). Meanwhile, van Rensen and Vermaas (1981) also found that the Hill reaction with ferricyanide does not require bicarbonate in trypsin-treated isolated broken pea in which ferricyanide accepts electrons directly at the $\mathrm{Q}_{\mathrm{A}}$ site (van Rensen \& Vermaas 1981). All the above findings proved that the site of the bicarbonate effect was between $\mathrm{Q}_{\mathrm{A}}$ and the plastoquinone pool.

Where are in specific sites of the bicarbonate effect? Many scientists have explored to reveal that some herbicides such as atrazine decrease the apparent affinity of the thylakoid membrane for bicarbonate when they studied the effects of bicarbonate and herbicides on electron transport in isolated chloroplasts, and suggested that the binding sites of bicarbonate are located on that of herbicide action (D1 protein) in Photosystem II (van Rensen and Vermaas 1981; Khanna et al. 1981; Snel and van Rensen 1983, 1984; Stemler and Murphy 1983).

Meanwhile, scientists demonstrate that bicarbonate is a bidentate ligand of the nonheme iron through measuring the electron paramagnetic resonance (EPR) spectra, and Mossbauer spectrum, examining Fourier transform infrared
(FTIR) difference spectroscopy (Bowden et al. 1991; Diner and Petrouleas 1987; Semin et al. 1990; Hienerwadel and Berthomieu 1995). Afterwards, scientists have also observed this bidentate ligand of the nonheme iron between two quinone acceptors in higher plants, algae, and cyanobacteria from crystal structure information (Guskov et al. 2010; Umena et al. 2011; Ago et al. 2016; Wei et al. 2016).On the one hand, bicarbonate in Photosystem II was deduced to stabilize the $\mathrm{Q}_{\mathrm{A}}-\mathrm{Fe}-\mathrm{Q}_{\mathrm{B}}$ structure, keep a fit distance between $\mathrm{Q}_{\mathrm{A}}$ and $\mathrm{Q}_{\mathrm{B}}$, accelerate the electron transfer between these two quinone acceptors by facilitating the protonation of reduced $\mathrm{Q}_{\mathrm{B}}$ (van Rensen et al. 1999; Shevela et al. 2012). On the other hand, the release of bicarbonate from the ligand can downregulate Photosystem II and oxygen evolution, thereby protect Photosystem II against photodamage (Brinkert et al. 2016). Besides, Tikhonov et al. (2017) quantified the amount of bicarbonate-bind per Photosystem II reaction center in spinach Photosystem II membrane fragments. The value of $1.1 \pm 0.1$ in bicarbonate-bind per Photosystem II reaction center demonstrated that Photosystem II binds one bicarbonate molecule as ligand to the non-heme iron (Tikhonov et al. 2018).

In the early 1970s, Stemler and Govindjee had observed the effect of bicarbonate on the donor side of Photosystem II, who found that bicarbonate increasing 4 to fivefold the rate of dichlorophenol indophenol reduction by isolated maize chloroplasts, and act close to the oxygen-evolving site (Stemler and Govindjee 1973). They deduced that one of the sites was before at or near the oxygen-evolving mechanism itself from chlorophyll $a$ fluorescence information (Stemler and Govindjee 1974).

Afterwards, many evidences demonstrated that bicarbonate plays roles in the donor side of Photosystem II. Assembly of the inorganic core of the oxygen-evolving center is an important role. Klimov et al. demonstrated that bicarbonate participates in the formation of the Mn-cluster, is essential for water oxidation in subchloroplast membrane fragments (Klimov et al. 1995a,b 1997). Allakhverdiev et al. (1997) demonstrated that bicarbonate is an essential constituent of the oxygen-evolving center of photosystem II (Allakhverdiev et al. 1997). Baranov et al. (2000, 2004) demonstrated that bicarbonate as a cofactor accelerates assembly of the manganese cluster of the photosynthetic water oxidizing complex in photosystem II (Baranov et al. 2000, 2004). Kozlov et al. (2010) demonstrated that the composition and stability of $\mathrm{Mn}^{3+}$-bicarbonate complexes is involved in photoinduced electron transfer from $\mathrm{Mn}^{2+}$ to reaction centers of photosystem II (Kozlov et al. 2010).

Mobile bicarbonate has a more interesting role. Shevela et al. (2013) found that free or weakly bound bicarbonate had a possible function at the water-splitting side of Photosystem II (Shevela et al. 2013). Koroidov et al. (2014) 
demonstrate that bicarbonate acts as a mobile proton acceptor during water oxidation (Koroidov et al. 2014).

Synthesizing evidences from the above two aspects as well as other works, and now it is currently acceptable that bicarbonate affect photosynthetic oxygen evolution on both the acceptor and the donor side of photosystem II (van Rensen et al. 1999; Stemler 2002, Shevela et al. 2012; Tikhonov et al. 2018).

\section{Bicarbonate effect neither in the acceptor side nor the donor side of Photosystem II}

In fact, it seems to has inadequate evidences to prove whether the acceptor or the donor or both side of Photosystem II during photosynthetic $\mathrm{O}_{2}$ evolution influenced by bicarbonate. In donor side of photosystem II, Shevela et al. (2008) found that bicarbonate is not a tightly bound constituent, has only 'indirect' effects on the oxygen-evolving center in Photosystem II using membrane-inlet mass spectrometry (MIMS) and isotope labelling techniques (Shevela et al. 2008). Aoyama et al. (2008) suggested that bicarbonate is neither a ligand nor a cofactor closely coupled to the oxygen-evolving Mn cluster in Photosystem II using Fourier transform infrared (FTIR) difference spectroscopy (Aoyama et al. 2008). Ulas et al. (2008) observed no tightly bound bicarbonate ions from the active site using mass spectrometry (Ulas et al. 2008). Clausen et al. (2005) was in contradiction with Koroidov et al. (2014) to exclude that exchangeable bicarbonate is the substrate for photosynthetic oxygen evolution (Clausen et al. 2005).

Similarly, bicarbonate affect photosynthetic $\mathrm{O}_{2}$ evolution on the acceptor side of Photosystem II was also questioned. Bowden et al. (1991) found that bound bicarbonate is absent at $\mathrm{pH} 6.0$, but present at $\mathrm{pH} 7.5$, and bicarbonate depleted isolated chloroplasts with displacement by another anion is not suitable to study bicarbonate effect as well as the status of bicarbonate binding (Bowden et al. 1991). van Rensen and Vermaas (1981) found the binding site for bicarbonate between quinone and plastoquinone in isolated thylakoid membranes of Synechococcus leopoliensis is absent, but this blue-green alga can release $\mathrm{O}_{2}$, indicating bound bicarbonate in the acceptor side of Photosystem II is not necessary for photosynthetic $\mathrm{O}_{2}$ evolution (van Rensen and Vermaas 1981). Fundamentally, bound bicarbonate to stabilize the $\mathrm{Q}_{\mathrm{A}}-\mathrm{Fe}-\mathrm{Q}_{\mathrm{B}}$ does not match the decay of the fluorescence intensity after three or more flashes. Crystal structure of oxygen-evolving Photosystem II does not display the bidentate ligand bound bicarbonate (Umena et al. 2011). Therefore, a more reasonable theoretical explanation is needed to settle the dispute under the considering all data and evidence on "bicarbonate effect".

\section{Bicarbonate as a direct substrate involving carbonic anhydrase}

Carbonic anhydrase (CA, EC 4.2.1.1) is ubiquitously found in most cells from all kingdoms of life, sometimes several forms exist in the same cell. CA catalyzed the reversible conversion of bicarbonate to carbon dioxide, which is one of the fastest enzymatic reactions. CA plays many physiological functions in photosynthesis, respiration, $\mathrm{pH}$ homeostasis and ion transport, etc.

The proportions of algal inorganic carbon sources or inorganic carbon utilization pathway was quantified using bidirectional isotope labeling tracer technique when Chlamydomonas reinhardtii and Chlorella pyrenoidosa was cultured in medium under different concentration of bicarbonate added (Wu et al. 2015). Both C. reinhardtii and $C$. pyrenoidosa have a great proportion of bicarbonate utilization pathway, larger than $76 \%$, or even close to $100 \%$. However, the proportion of bicarbonate added as algal inorganic carbon sources, which increases with the increasing concentration of bicarbonate added, is small (Table 1). It demonstrates that $C$. reinhardtii or $C$. pyrenoidosa assimilate bicarbonate not only as a direct substrate, but also as most dominant way for inorganic carbon assimilation. However, CA is completely inhibited when the culture medium adding $10.0 \mathrm{mmol} / \mathrm{L}$ acetazolamide, an inhibitor of extracellular CA. In this time, the pathway of utilization bicarbonate by algae, which increases with the increasing concentration of bicarbonate added, decreases dramatically (Table 2). It suggests that $\mathrm{CA}$ is convenient to that photosynthetic organisms use bicarbonate as a direct substrate (Wu et al. 2015).

\section{Thylakoid CA versus photosynthetic oxygen evolution}

\section{Photosystem II indeed possessed CA activity}

There are two types of CA in the chloroplast, one was a soluble CA located in the stroma, a second was tightly bound to thylakoids membranes, called thylakoid CA (tCA) (Komarova et al. 1982; Pronina et al. 2002; Moskvin et al. 2004; Rudenko et al. 2006, 2007). Many studies of tCA from maize (Stemler 1986), wheat (Khristin et al. 2004), pea (Moskvin et al. 1995) and Arabidopsis (Ignatova et al. 2011) chloroplasts showed the association of enzymatic activity with Photosystem II. A lot of evidence showed that Photosystem II indeed possessed CA activity.

Acetazolamide inhibits photosynthetic electron transfer in Photosystem II and the acetazolamide-induced inhibition is totally reversed by the addition of bicarbonate (Shitov 
Table 1 The proportion of carbon sources and utilization pathway when $C$. reinhardtii and $C$. pyrenoidosa was cultured in medium under different concentration of bicarbonate added ( $\mathrm{Wu}$ et al. 2015)

\begin{tabular}{|c|c|c|c|c|c|c|}
\hline \multirow[t]{2}{*}[\mathrm{NaHCO}_{3}]{$* /(\mathrm{mmol} / \mathrm{L})$} & \multicolumn{3}{|l|}{ C. reinhardtii } & \multicolumn{3}{|c|}{ C. pyrenoidosa } \\
\hline & $\mathrm{P}$ & $f_{B}$ & $f_{b}$ & $\mathrm{P}$ & $f_{B}$ & $f_{b}$ \\
\hline 0 & $3.51 \pm 0.27$ & 0.00 & 0.96 & $4.24 \pm 0.22$ & 0.00 & 0.77 \\
\hline 0.50 & $4.00 \pm 0.30$ & 0.02 & 0.97 & $4.31 \pm 0.22$ & 0.03 & 0.81 \\
\hline 2.00 & $4.11 \pm 0.18$ & 0.09 & $1.00(1.05) \S$ & $4.51 \pm 0.23$ & 0.08 & 0.92 \\
\hline 4.00 & $4.26 \pm 0.20$ & 0.18 & $1.00(1.02) \S$ & $5.28 \pm 0.17$ & 0.17 & $1.00(1.10) \S$ \\
\hline 8.00 & $4.97 \pm 0.23$ & 0.30 & $1.00(1.10) \S$ & $4.67 \pm 0.21$ & 0.41 & $1.00(1.29) \S$ \\
\hline
\end{tabular}

The data is represented by mean $\pm \mathrm{SE}(n=3 \sim 4)$. P, the algal proliferation multiple; $f_{B}$, the proportion of bicarbonate added as carbon sources to the whole carbon sources used by microalgae; $f_{b}$, the proportion of bicarbonate utilization pathway to the whole carbon utilization pathway of microalgae; *The initial concentration of $\mathrm{NaHCO}_{3}$ added in medium; §The data in brackets were calculated values, whereas those out of brackets were corrected values considering the errors from the determination of $\delta^{13} \mathrm{C}$ and the difference induced by growth status

\begin{tabular}{|c|c|c|c|c|c|c|}
\hline \multirow[t]{2}{*}[\mathrm{NaHCO}_{3}]{$* /(\mathrm{mmol} / \mathrm{L})$} & \multicolumn{3}{|l|}{ C. reinhardtii } & \multicolumn{3}{|c|}{ C. pyrenoidosa } \\
\hline & $\mathrm{P}$ & $f_{B}$ & $f_{b}$ & $\mathrm{P}$ & $f_{B}$ & $f_{b}$ \\
\hline 0 & $2.40 \pm 0.22$ & 0.00 & $0.00(-0.28) \S$ & $2.11 \pm 0.17$ & 0.00 & $0.00(-0.42) \S$ \\
\hline 0.50 & $2.88 \pm 0.24$ & 0.00 & $0.00(-0.05) \S$ & $2.53 \pm 0.25$ & 0.03 & $0.00(-0.24) \S$ \\
\hline 2.00 & $2.97 \pm 0.24$ & 0.17 & 0.11 & $3.09 \pm 0.22$ & 0.18 & 0.02 \\
\hline 4.00 & $3.40 \pm 0.21$ & 0.23 & 0.24 & $3.22 \pm 0.22$ & 0.26 & 0.05 \\
\hline 8.00 & $3.55 \pm 0.19$ & 0.34 & 0.18 & $4.02 \pm 0.19$ & 0.34 & 0.08 \\
\hline
\end{tabular}

Same as that of Table 1
Table 2 The proportion of carbon sources and utilization pathway when $C$. reinhardtii and $C$. pyrenoidosa was cultured in medium with $10.0 \mathrm{mmol} / \mathrm{L}$ acetazolamide under different concentration of bicarbonate added ( $\mathrm{Wu}$ et al. 2015) et al. 2011). Meanwhile, acetazolamide and imidazole suppressed the the photoinduced yield of chlorophyll fluorescence (Pronina et al. 2002). Formate, an anionic inhibitors, similarly decreased tCA activity, and the inhibition of other anionic inhibitors, such as bicarbonate, $\mathrm{I}^{-}$, is same for both Photosystem II and tCA activity (Stemler 1980, 1986).

Both tCA and Photosystem II photosynthetic activities are inhibited by $\mathrm{Zn}^{2+}$ (Tripathy and Mohanty 1980; Rashid et al. 1991; Stemler 1997). The effects of $\mathrm{Cl}^{-}$on tCA was similar to that on Photosystem II activities (Stemler 1986, 1997; Lu and Stemler 2007). The effects of $\mathrm{Ca}^{2+}$ and $\mathrm{Mn}^{2+}$ on tCA was also similar to that on Photosystem II activities (Stemler 1986, 1997; Lu and Stemler 2007).

Photosystem II inhibitors, 3-(3,4-dichlorophenyl)-1,1'dimethylurea (DCMU) and hydroxylamine, similarly inhibited the activity of tCA (Rudenko et al. 2015). Strong light inhibited both tCA activity and electron transport of Photosystem II, induced photoinhibition, and Photosystem II modifiers hydroxylamine and atrazine prevented this "photoinhibition" (Stemler 1986; Kyle et al. 1984).

The unique characteristics of tCA among known CA types was that tCA activity was sensitive to the surrounding redox-potential, and was similar with that of Photosystem II (Bearden and Malkin 1973; Stemler and Jursinic 1993; Moubarak-Milad and Stemler 1994). Far-red light also stimulates both the tCA activity and Hill reaction of Photosystem II (Govindjee et al. 1960; Stemler 1997). In addition, maize mesophyll chloroplasts were found that an antibody produced against Chlamydomonas reinhardtii's thylakoid lumen $\mathrm{CA}(\mathrm{Cah} 3)$ reacts with a protein in enriched Photosystem II membranes (Lu and Stemler 2002).

Actually, in the last two decades, it is widely accepted this view that Photosystem II possessed CA activity. Numerous studies on the nature of tCA have shown that Photosystem II-membranes of plants, such as maize, pea, wheat, spinach, Chlamydomonas reinhardtii, Thermosynechococcus elongatus, Arthrospira maxima, contained two CAs, one was called extrinsic CA, is removable by washing PSII membrane fragments with $1 \mathrm{M} \mathrm{CaCl}_{2}$, the other tightly associated with the core Photosystem II complex called as intrinsic CA (Dai et al. 2001; Lu and Stemler 2002; Villarejo et al. 2002; Khristin et al. 2004; Moskvin et al. 2004; Ignatova et al. 2006; Hillier et al. 2006; Rudenko et al. 2006, 2007; Enami et al. 2008; Shitov et al. 2009).

According to the known data, there are great differences in the characteristics between the extrinsic CA and the intrinsic CA of Photosystem II, such as Table 3. 
Table 3 The difference of the characteristics of CAs in Photosystem II-membranes

\begin{tabular}{|c|c|c|c|c|}
\hline Characteristics & Intrinsic CA & Extrinsic CA & Materials & References \\
\hline Position in Photosystem II & $\begin{array}{l}\text { Photosystem II core- } \\
\text { complex }\end{array}$ & $\begin{array}{l}\text { Near Photosystem II at the lumenal } \\
\text { side of thylakoid membrane, in the } \\
\text { vicinity of the OEC }\end{array}$ & Pea & $\begin{array}{l}\text { Khristin et al. 2004; Lu } \\
\text { and Stemler 2002; } \\
\text { Shitov et al. 2009; }\end{array}$ \\
\hline Effect of $\mathrm{Cl}^{-}$ & $\begin{array}{l}\text { Continue to increase } \\
\text { the activity up to at } \\
\text { least } 400 \mathrm{mM}\end{array}$ & $\begin{array}{l}\text { Maximum of activity at } 5 \sim 20 \mathrm{mM}, \\
\text { afterwards declined, no activity at } \\
80 \mathrm{mM}\end{array}$ & Maize, Pea & Lu and Stemler 2007 \\
\hline Effect of $\mathrm{pH}$ & $\begin{array}{l}\text { The hydration activity } \\
\text { insensitive to } \mathrm{pH}\end{array}$ & $\begin{array}{l}\text { The highest dehydration activity at } \mathrm{pH} \\
\text { below } 6 \text {, and immeasurable above } \\
6.5\end{array}$ & Maize & Lu and Stemler 2007 \\
\hline Direction of reaction & hydration & dehydration & Maize & $\mathrm{Lu}$ and Stemler 2007 \\
\hline Effect of Triton X-100 & $\begin{array}{l}\text { Maximum of activity } \\
\text { at triton/Chl ratio of } \\
1.0\end{array}$ & No detected effect & Pea & $\begin{array}{l}\text { Pronina et al. 2002; } \\
\quad \text { Khristin et al. } 2004\end{array}$ \\
\hline Sulfonamide inhibitors action & $\begin{array}{l}\text { High sensitivity to } \mathrm{EZ} \\
\text { with } \mathrm{I}_{50}=10^{-9} \mathrm{M}\end{array}$ & $\begin{array}{l}\text { Stimulation of activity by } \mathrm{AZ} \\
\left(\text { at } 10^{-8}-10^{-5} \mathrm{M}\right) \text {, high sensitivity } \\
\text { to EZ with } \mathrm{I}_{50}=10^{-9} \mathrm{M}\end{array}$ & $\begin{array}{l}\text { Pea, } \\
\text { Arabidopsis } \\
\text { thaliana }\end{array}$ & $\begin{array}{l}\text { Ignatova et al. 2006; } \\
\quad \text { Shitov et al. 2009, } 2011\end{array}$ \\
\hline Effect of divalent cations & ND & $\begin{array}{l}\text { Stimulation of activity by } \mathrm{Mn}^{2+} \\
\text { inhibition of activity by } \mathrm{Zn}^{2+}\end{array}$ & Pea & Shitov et al. 2009 \\
\hline Apparent molecular mass & $?$ & $33 \mathrm{kD}, 50 \mathrm{kD}, 24 \mathrm{kD}, 18 \mathrm{kD}$ & Pea & $\begin{array}{l}\text { Lu and Stemler 2002; } \\
\text { Rudenko et al. 2006; } \\
\text { Shitov et al. } 2009\end{array}$ \\
\hline Site of bicarbonate-bound & ? & None & Spinach & Tikhonov et al. 2018 \\
\hline
\end{tabular}

AZ, Acetazolamide; EZ, Ethoxyzolamide; OEC, Oxygen-evolving center; ND, No detecting

\section{Photosystem II core-complex with the carrier of photosynthetic $\mathrm{O}_{2}$ evolution and $\mathrm{CA}$ activity not $\mathrm{CA}$ in the conventional sense}

According to Table 3, there are quite different properties among the extrinsic CA, the intrinsic CA in Photosystem II and the soluble $\mathrm{CA}$, and the functions they perform are also quite different. So far, the intrinsic CA of Photosystem II has not been isolated. Some inhibitors exhibit good inhibitory effect on CA in Photosystem II, but do not affect much photosynthetic activity (Rodionova et al. 2017). Although some inhibitors can inhibit the activity both photosynthetic and CA in Photosystem II, the degree of inhibition is different. For example, one of the $\mathrm{Cu}$ (II)phenyl sulfonylhydrazone complexes inhabits CA activity of Photosystem II by $100 \%$, but the Photosystem II photosynthetic activity by only 66.2\% (Karacan et al. 2014). The activity of oxygen evolution was suppressed, but that of the intrinsic CA in Photosystem II was unchanged after removing manganese clusters, which demonstrated that CA activity was not directly correlated with $\mathrm{O}_{2}$ evolution activity, and is independent of the presence of manganese clusters (Dai et al. 2001). The CA (CA[Mn]) manganesesubstituted the active-site zinc functions as peroxidase, and produces $\mathrm{O}_{2}$ in the presence of hydrogenperoxide and bicarbonate (Okrasa \& Kazlauskas 2006). It can be seen that Photosystem II core-complex has not only the activity of photosynthetic $\mathrm{O}_{2}$ evolution, but also that of CA. The manganese clusters $\left(\mathrm{Mn}_{4} \mathrm{CaO}_{5}\right)$, which oxygen atoms as oxo bridges linking the manganese atoms may be catalyzed for dioxygen formation to produce oxygen (Umena et al. 2011), were involved in photosynthetic $\mathrm{O}_{2}$ evolution of Photosystem II. However, Photosystem II core-complex itself cannot be isolated, and its properties are obviously different from common zinc-contained CA. Therefore, it can be said that Photosystem II core-complex is the carrier of photosynthetic oxygen evolution and CA activity not $\mathrm{CA}$ in the conventional sense.

\section{Dehydration and hydration of thylakoid CA depended on $\mathrm{pH}$}

Oxygen evolution of Chlorella illuminated in the presence of nitrate completely ceases when carbon dioxide is absorbed by alkali (Warburg et al.1965), it demonstrates that the premise of oxygen evolution should be in present of inorganic carbon. Moreover, Koroidov et al. (2014) proved that that bicarbonate functions not only as a mobile proton acceptor, but also results in a light-driven production of both $\mathrm{O}_{2}$ and $\mathrm{CO}_{2}$ (Koroidov et al. 2014). Meanwhile, bicarbonate was found that it fit to act as a tridentate bridge between $\mathrm{Mn}^{\mathrm{IV}}$ and $\mathrm{Ca}^{2+}$ in architecture of the photosynthetic oxygen-evolving center (Ferreira 2004). These evidences seem to demonstrate that bicarbonate rather than water as direct substrate take part in photosynthetic $\mathrm{O}_{2}$ evolution. Water incorporating $\mathrm{CO}_{2}$ into bicarbonate was 
mistaken for direct substrate during photosynthetic $\mathrm{O}_{2}$ evolution.

Whether on the acceptor or on the donor of side of Photosystem II, existence of bicarbonate binding is uncertainty, which depends on pH (Bowden et al. 1991). $\mathrm{Lu}$ and Stemler (2007) showed that intrinsic CA in Photosystem II core-complex just had the hydration activity insensitive to $\mathrm{pH}$, and extrinsic $\mathrm{CA}$ in the vicinity of the oxygen-evolving center just had the dehydration activity sensitive to $\mathrm{pH}$, the highest dehydration activity was at $\mathrm{pH}$ below 6, and immeasurable above 6.5. Moreover, the hydration activity of intrinsic CA in Photosystem II corecomplex is greater 5 times than the dehydration activity of extrinsic CA ( $\mathrm{Lu}$ and Stemler 2007). It suggests that the photosynthetic $\mathrm{O}_{2}$ evolution of Photosystem II core-complex is accompanied by the hydrolysis of inorganic carbon. Similarly, it is demonstrated that that bicarbonate as direct substrate take part in photosynthetic $\mathrm{O}_{2}$ evolution. Photosystem II core-complex should be definited inorganic carbon oxidase/hydrolase opposite to Ribulose-1,5bisphosphate carboxylase/oxygenase (Rubisco). The dehydration of extrinsic CA provides protons, and the hydration of intrinsic CA provides bicarbonate for photosynthetic oxygen evolution. PSII core-complex combined with extrinsic CA provides two basic substrates, proton and bicarbonate, for photosynthetic oxygen evolution. The equation of photosynthetic oxygen evolution in Photosystem II was written as following:

$\mathrm{H}^{+}+\mathrm{HCO}_{3}^{-} \rightarrow 1 / 2 \mathrm{O}_{2}+2 \mathrm{e}^{-}+2 \mathrm{H}^{+}+\mathrm{CO}_{2}$

Additionally, the bicarbonate-bind as ligand to the nonheme iron on the acceptor side of Photosystem II depended on the $\mathrm{pH}$, which was influenced by the coupling of Photosystem I. When the protons produced by photosynthetic $\mathrm{O}_{2}$ evolution were moved through Photosystem I, the $\mathrm{pH}$ increased, and the ligand is present. Otherwise, the ligand is absent (Bowden et al. 1991). The consumption of protons by Photosystem I regulates the electron flow and photophosphorylation in Photosystem II (Carr and Axelsson 2008; Fedorchuk et al. 2018), and eventually, adjusts photosynthetic $\mathrm{O}_{2}$ evolution. That is to say, another function of bicarbonate is to regulate photosynthetic $\mathrm{O}_{2}$ evolution.

\section{Evolution of Earth's environment versus photosynthetic $\mathrm{O}_{2}$ evolution using bicarbonate as a direct substrate}

Obviously, if plants would not consume bicarbonate as a direct substrate during photosynthesis, it is difficult to explain the evolution of Earth's environment. The concentration of $\mathrm{CO}_{2}$ in the Archean atmosphere before 2500 million years was $0.9 \sim 900 \mathrm{kPa}$, and that in Contemporary atmosphere only $0.03 \mathrm{kPa}$. Correspondingly, the concentration of bicarbonate in the Archean seawater was $15 \sim 15,000 \mathrm{mM}$, and that in Contemporary seawater $2 \mathrm{mM}$ (Dismukes et al. 2001). If the photosynthetic organisms assimilated only $\mathrm{CO}_{2}$ in the Archean atmosphere, bicarbonate in the Archean seawater decreased depending on dissociation equilibrium. The hydroxide ion in the Archean seawater would not increase. As the system in the Archean seawater with high concentration of carbonic acid and bicarbonate was buffer, the $\mathrm{pH}$ value would not change. In fact, it is estimated that seawater $\mathrm{pH}$ gradually increased from $\sim 6.5$ and 7.0 of Archean to $\sim 7.5$ and 9.0 of Phanerozoic (Halevy \& Bachan 2017). It partly accounts for the increase of $\mathrm{pH}$ in seawater which marine organisms utilized bicarbonate as the direct substrate during photosynthesis. In the Archean seawater, organisms used bicarbonate as a direct substrate, and reduced the concentration of bicarbonate during photosynthesis. Meanwhile, hydrogen ions in environment simultaneously entered the organism to achieve an electrochemical balance, resulting in the rise of $\mathrm{pH}$ in the Archean seawater.

\section{Thermodynamic convenience of bicarbonate photolysis}

Thermodynamically, the standard free energy differences in the chemical equilibria, $\mathrm{H}_{2} \mathrm{O} \rightarrow 1 / 2 \mathrm{O}_{2}+2 \mathrm{e}^{-}+2 \mathrm{H}^{+}$, was $37.3 \mathrm{kcal} / \mathrm{mol}$, and that in the chemical equilibria, $\mathrm{H}^{+}+\mathrm{HCO}_{3}^{-} \rightarrow 1 / 2 \quad \mathrm{O}_{2}+2 \mathrm{e}^{-}+2 \mathrm{H}^{+}+\mathrm{CO}_{2}$, $24.8 \mathrm{kcal} / \mathrm{mol}$ (Dismukes et al. 2001). The free energy required for $\mathrm{O}_{2}$ evolution using bicarbonate as the substrate is significantly lower than that using water as the substrate during photosynthesis of organisms. Therefore, the photosynthetic organisms may be more likely to photolysis bicarbonate to release $\mathrm{O}_{2}$ and $\mathrm{CO}_{2}$, then $\mathrm{CO}_{2}$ incorporate into the Calvin cycle for carbon fixation.

\section{Reexamining the isotopic evidence}

We reexamine the isotopic evidence that bicarbonate is not the direct substrate of photosynthetic $\mathrm{O}_{2}$ release according to our previous work (Wu et al. 2015). From the experiment of Metzner et al. (1979), it can be found that at least $39 \%$ of oxygen release from bicarbonate during light reaction in photosynthesis of Ankistrodesmus braunii by using isotope binary mixture model when the algae were absent in CA activity. The proportion of photosynthetic $\mathrm{O}_{2}$ from bicarbonate will be larger when Ankistrodesmus braunii were present in CA activity. 
In $\mathrm{HC}^{18} \mathrm{O}_{3}{ }^{-}$labelling experiment from Radmer and Ollinger (1980), the results can be interpreted as that $\mathrm{HC}^{18} \mathrm{O}_{3}{ }^{-}$added in reaction system firstly took place the chemical equilibria, $\mathrm{H}^{+}+\mathrm{HC}^{18} \mathrm{O}_{3}{ }^{-} \leftrightarrow \mathrm{H}_{2}{ }^{18} \mathrm{O}+\mathrm{C}^{18} \mathrm{O}_{2}$, then,

$$
\mathrm{H}_{2}{ }^{16} \mathrm{O}\left(\mathrm{H}_{2}{ }^{18-}\right.
$$

$\mathrm{O})+\mathrm{C}^{16} \mathrm{O}_{2}\left(\mathrm{C}^{18} \mathrm{O}_{2}\right) \leftrightarrow \mathrm{H}^{+}+\mathrm{HC}^{16} \mathrm{O}_{3}{ }^{-}\left(\mathrm{HC}^{18} \mathrm{O}_{3}{ }^{-}\right)$. The isotopic composition of the $\mathrm{CO}_{2}$ at the beginning of the flash was $\mathrm{C}^{18} \mathrm{O}_{2}, 0.031 ; \mathrm{C}^{16,18} \mathrm{O}_{2}, 0.320 ; \mathrm{C}^{18} \mathrm{O}_{2}, 0.649$. Therefore, $\mathrm{C}^{18} \mathrm{O}_{2}$ forming $\mathrm{HC}^{18} \mathrm{O}_{3}{ }^{-}$again accounts for only $23.6 \%$ of the total $\mathrm{CO}_{2}$ in the system. Meanwhile, $\mathrm{H}_{2}{ }^{18} \mathrm{O}$ forming $\mathrm{HC}^{18} \mathrm{O}_{3}{ }^{-}$again accounts for less than $5 \%$ of the total $\mathrm{H}_{2}{ }^{18} \mathrm{O}$ in the system with $10 \mathrm{mM}$ of bicarbonate. That is said that less than $5 \%$ of the oxygen release from $\mathrm{HC}^{18} \mathrm{O}_{3}{ }^{-}$. This is consistent with the experimental results of Radmer \& Ollinger (1980). However, here, the explanation is obviously different from theirs. I debate to propose that bicarbonate is directly used as substrate to participate in photosynthetic $\mathrm{O}_{2}$ evolution, resulting in the chemical equilibria, $\mathrm{H}^{+}+\mathrm{HCO}_{3}{ }^{-} \rightarrow 1 / 2$ $\mathrm{O}_{2}+2 \mathrm{e}^{-}+2 \mathrm{H}^{+}+\mathrm{CO}_{2}$, which provides with electrons, and accumulates $\mathrm{CO}_{2}$ into Calvin cycle for photosynthetic carbon assimilation. The same interpretation was suitable to apply in the work of Stemler \& Radmer (1975).

\section{Conclusions}

It is generally accepted that $\mathrm{O}_{2}$ released by plants come from water in photosynthesis, which should be debated. In fact, bicarbonate is directly used as substrate to participate in photosynthetic $\mathrm{O}_{2}$ evolution, resulting in the chemical equilibria, $\mathrm{H}^{+}+\mathrm{HCO}_{3}^{-} \rightarrow 1 / 2 \quad \mathrm{O}_{2}+2 \mathrm{e}^{-}+2 \mathrm{H}^{+-}$ $+\mathrm{CO}_{2}$, which provides with electrons, and accumulates $\mathrm{CO}_{2}$ into Calvin cycle for photosynthetic carbon assimilation.

Acknowledgements We thank the foundations of the National Key Research and Development Program of China [2016YFC0502602], the National Natural Science Foundation of China [No. U1612441-2], and Support Plan Projects of Science and Technology Department of Guizhou Province [No. (2021)YB453].

\section{Declarations}

Conflicts of interest The author declares no conflict of interest.

Open Access This article is licensed under a Creative Commons Attribution 4.0 International License, which permits use, sharing, adaptation, distribution and reproduction in any medium or format, as long as you give appropriate credit to the original author(s) and the source, provide a link to the Creative Commons licence, and indicate if changes were made. The images or other third party material in this article are included in the article's Creative Commons licence, unless indicated otherwise in a credit line to the material. If material is not included in the article's Creative Commons licence and your intended use is not permitted by statutory regulation or exceeds the permitted use, you will need to obtain permission directly from the copyright holder. To view a copy of this licence, visit http://creativecommons. org/licenses/by/4.0/.

\section{References}

Ago H, Adachi H, Umena Y, Tashiro T, Kawakami K, Kamiya N, Tian L, Han G, Kuang T, Liu Z, Wang F, Zou H, Enami I, Miyano M, Shen JR (2016) Novel features of eukaryotic photosystem II revealed by its crystal structure analysis from a red alga. J Biol Chem 291(11):5676-5687

Allakhverdiev SI, Yruela I, Picorel R, Klimov VV (1997) Bicarbonate is an essential constituent of the water-oxidizing complex of photosystem II. P Nati Acad Sci USA 94(10):5050-5054

Aoyama C, Suzuki H, Sugiura M, Noguchi T (2008) Flash-induced FTIR difference spectroscopy shows no evidence for the structural coupling of bicarbonate to the oxygen-evolving $\mathrm{Mn}$ cluster in photosystem II. Biochemistry 47(9):2760-2765

Baranov SV, Ananyev GM, Klimov VV, Dismukes GC (2000) Bicarbonate accelerates assembly of the inorganic core of the water-oxidizing complex in manganese-depleted photosystem II: a proposed biogeochemical role for atmospheric carbon dioxide in oxygenic photosynthesis. Biochemistry 39(20):6060-6065

Baranov SV, Tyryshkin AM, Katz D, Dismukes GC, Klimov VV (2004) Bicarbonate is a native cofactor for assembly of the manganese cluster of the photosynthetic water oxidizing complex. Kinetics of reconstitution of $\mathrm{O}_{2}$ evolution by photoactivation. Biochemistry 43:2070-2079

Bearden AJ, Malkin R (1973) Oxidation-reduction potential dependence of low-temperature photoreactions of chloroplast photosystem II. BBA-Bioenerg 325(2):266-275

Bowden SJ, Hallahan BJ, Ruffle SV, Evans MCW, Nugent JHA (1991) Preparation and characterization of Photosystem II core particles with and without bound bicarbonate. BBA-Bioenerg 1060(1):89-96

Brinkert K, De Causmaecker S, Krieger-Liszkay A, Fantuzzi A, Rutherford AW (2016) Bicarbonate-induced redox tuning in photosystem II for regulation and protection. P Nati Acad Sci USA 113:12144-12149

Carr H, Axelsson L (2008) Photosynthetic utilization of bicarbonate in Zostera marina is reduced by inhibitors of mitochondrial ATPase and electron transport. Plant Physiol 147(2):879-885

Clausen J, Beckmann K, Junge W, Messinger J (2005) Evidence that bicarbonate is not the substrate in photosynthetic oxygen evolution. Plant Physiol 139(3):1444-1450

Crane FL, Barr R (1977) Stimulation of photosythesis by carbonyl compounds and chelators. Biochem Bioph Res Co 74:1362-1368

Dai X, Yu Y, Zhang R, Yu X, He P, Xu C (2001) Relationship among photosystem II carbonic anhydrase, extrinsic polypeptides and manganese cluster. Chin Sci Bull 46(5):406-408

Dismukes GC, Klimov VV, Baranov SV, Kozlov YN, DasGupta J, Tyryshkin A (2001) The origin of atmospheric oxygen on Earth: the innovation of oxygenic photosynthesis. P Nati Acad Sci USA 98(5):2170-2175

Enami I, Okumura A, Nagao R, Suzuki T, Iwai M, Shen JR (2008) Structures and functions of the extrinsic proteins of photosystem II from different species. Photosynth Res 98(1-3):349-363

Fedorchuk TP, Opanasenko VK, Rudenko NN, Ivanov BN (2018) Bicarbonate-induced stimulation of photophosphorylation in isolated thylakoids: effects of carbonic anhydrase inhibitors. Biol Membrany 35(1):34-41

Ferreira KN (2004) Architecture of the photosynthetic oxygenevolving center. Science 303(5665):1831-1838 
Govindjee R, Thomas JB, Rabinowitch E (1960) Second emerson effect in the hill reaction of chlorella cells with quinone as oxidant. Science 132(3424):421-421

Govindjee PMJP, Govindjee R, van Gorkom HJ, Duysens LNM (1976) Inhibition of the reoxidation of the secondary electron acceptor of photosystem II by bicarbonate depletion. BBABioenerg 449:602-605

Guskov A, Gabdulkhakov A, Broser M, Glöckner C, Hellmich J, Kern J, Frank J, Müh F, Saenger W, Zouni A (2010) Recent progress in the crystallographic studies of photosystem II. ChemPhysChem 11(6): 1160-1171

Halevy I, Bachan A (2017) The geologic history of seawater $\mathrm{pH}$. Science 355(6329):1069-1071

Hillier W, McConnell I, Badger MR, Boussac A, Klimov VV, Dismukes GC, Wydrzynski T (2006) Quantitative assessment of intrinsic carbonic anhydrase activity and the capacity for bicarbonate oxidation in photosystem II. Biochemistry 45(7):2094-2102

Ignatova LK, Rudenko NN, Khristin MS, Ivanov BN (2006) Heterogeneous origin of carbonic anhydrase activity of thylakoid membranes. Biochem-Mosc 71:525-532

Ignatova LK, Rudenko NN, Mudrik VA, Fedorchuk TP, Ivanov BN (2011) Carbonic anhydrase activity in arabidopsis thaliana thylakoid membrane and fragments enriched with PSI or PSII. Photosynth Res 110:89-98

Jursinic P, Stemler A (1986) Correlation between the binding of formate and decreased rates of charge transfer through the photosystem II quinones. Photochem Photobiol 43(2):205-212

Karacan MS, Zharmukhamedov SK, Mamaş S, Kupriyanova EV, Shitov AV, Klimov VV, Özbek N, Özmen Ü, Gündüzalp A, Schmitt F, Karacan N, Friedrich T, Los DA, Carpentier R, Allakhverdiev SI (2014) Screening of novel chemical compounds as possible inhibitors of carbonic anhydrase and photosynthetic activity of photosystem II. J Photoch Photobio B 137:156-167

Khanna R, Pfister K, Keresztes A, van Rensen JJS, Govindjee (1981) Evidence for a close spatial location of the binding sites for $\mathrm{CO}_{2}$ and for photosystem II inhibitors. BBA-Bioenerg 634:195-211

Khristin MS, Ignatova LK, Rudenko NN, Ivanov BN, Klimov VV (2004) Photosystem II associated carbonic anhydrase activity in higher plants is situated in core complex. FEBS Lett 577:305-308

Klimov VV, Allakhverdiev SI, Baranov SV, Feyziev YM (1995a) Effects of bicarbonate and formate on the donor side of photosystem 2. Photosynth Res 46(1-2):219-225

Klimov VV, Allakhverdiev SI, Feyziev YM, Baranov SV (1995b) Bicarbonate requirement for the donor side of photosystem II. FEBS Lett 363(3):251-255

Klimov VV, Baranov SV, Allakhverdiev SI (1997) Bicarbonate protects the donor side of photosystem II against photoinhibition and thermoinactivation. FEBS Lett 418(3):243-246

Komarova IM, Doman NG, Shaposhnikov GL (1982) Two forms of carbonic anhydrase in beans chloroplasts. Biokhimiya 47:1027-1034

Koroidov S, Shevela D, Shutova T, Samuelsson G, Messinger J (2014) Mobile hydrogen carbonate acts as proton acceptor in photosynthetic water oxidation. P Nati Acad Sci USA 111(17):6299-6304

Kozlov YN, Tikhonov KG, Zastrizhnaya OM, Klimov VV (2010) pH dependence of the composition and stability of $\mathrm{Mn}^{\mathrm{III}}$-bicarbonate complexes and its implication for redox interaction of $\mathrm{Mn}^{\mathrm{II}}$ with photosystem II. J Photoch Photobio B 101(3):362-366

Kyle DJ, Ohad I, Amtzen CJ (1984) Membrane protein damage and repair: selective loss of a quinone-protein function in chloroplast membranes. P Nati Acad Sci USA 81:4070-4074
Lu YK, Stemler AJ (2002) Extrinsic photosystem II carbonic anhydrase in maize mesophyll chloroplasts. Plant Physiol 128(2):643-649

Lu YK, Stemler AJ (2007) Differing responses of the two forms of photosystem II carbonic anhydrase to chloride, cations, and $\mathrm{pH}$. BBA-Bioenerg 1767:633-638

Metzner H, Fischer K, Bazlen O (1979) Isotope ratios in photosynthetic oxygen. BBA-Bioenerg 548(2):287-295

Moskvin OV, Ignatova LK, Ovchinnikova VI, Ivanov BN (1995) Membrane-associated carbonic anhydrase of pea thylakoids. Biokhimiya 60:130-1137

Moskvin OV, Shutova TV, Khristin MS, Ignatova LK, Villarejo A, Samuelsson G, Ivanov BN (2004) Carbonic anhydrase activities in pea thylakoids. Photosynth Res 79(1):93-100

Moubarak-Milad M, Stemler A (1994) Oxidation-reduction potential dependence of photosystem II carbonic anhydrase in maize thylakoids. Biochemistry 33(14):4432-4438

Okrasa K, Kazlauskas RJ (2006) Manganese-substituted carbonic anhydrase as a new peroxidase. Chem-Eur J 12(6):1587-1596

Pronina NA, Allakhverdiev SI, Kupriyanova EV, Klyachko-Gurvich GL, Klimov VV (2002) Carbonic anhydrase in subchloroplast particles of pea plants. Russ J Plant Physl 49(3):303-310

Radmer R, Ollinger O (1980) Isotopic composition of photosynthetic $\mathrm{O}_{2}$ flash yields in the presence of $\mathrm{H}_{2}{ }^{18} \mathrm{O}$ and $\mathrm{HC}^{18} \mathrm{O}_{3}{ }^{-}$. FEBS Lett 110(1):57-61

Rashid A, Bemier M, Pazdemick L, Catpentier R (1991) Interaction of $\mathrm{Zn}^{2+}$ with the donor side of photosystem II. Photosynth Res 30(2-3):123-130

Rodionova MV, Zharmukhamedov SK, Karacan MS, Venedik KB, Allakhverdiev SI (2017) Evaluation of new cu(II) complexes as a novel class of inhibitors against plant carbonic anhydrase, glutathione reductase, and photosynthetic activity in photosystem II. Photosynth Res 133(1):1-15

Rudenko NN, Ignatova LK, Kamornitskaya VB, Ivanov BN (2006) Pea leaf thylakoids contain several carbonic anhydrases. Dokl Biochem Biophys 408(1):155-157

Rudenko NN, Ignatova LK, Ivanov BN (2007) Multiple sources of carbonic anhydrase activity in pea thylakoids: soluble and membrane-bound forms. Photosynth Res 91(1):81-89

Rudenko NN, Ignatova LK, Fedorchuk TP, Ivanov BN (2015) Carbonic anhydrases in photosynthetic cells of higher plants. Biochem-Mosc 80(6):674-687

Shevela D, Su JH, Klimov V, Messinger J (2008) Hydrogencarbonate is not a tightly bound constituent of the water-oxidizing complex in photosystem II. BBA-Bioenerg 1777(6):532-539

Shevela D, Eaton-Rye JJ, Shen JR, Govindjee (2012) Photosystem II and the unique role of bicarbonate: a historical perspective. BBA-Bioenerg 1817(8):1134-1151

Shevela D, Nöring B, Koroidov S, Shutova T, Samuelsson G, Messinger J (2013) Efficiency of photosynthetic water oxidation at ambient and depleted levels of inorganic carbon. Photosynth Res 117:401-412

Shitov AV, Pobeguts OV, Smolova TN, Allakhverdiev SI, Klimov VV (2009) Manganese-dependent carboanhydrase activity of photosystem II proteins. Biochem-Mosc 74(5):509-517

Shitov AV, Zharmukhamedov SK, Shutova TV, Allakhverdiev SI, Samuelsson G, Klimov VV (2011) A carbonic anhydrase inhibitor induces bicarbonate-reversible suppression of electron transfer in pea photosystem 2 membrane fragments. J Photoch Photobio B 104(1-2):366-371

Snel JFH, van Rensen JJS (1983) Kinetics of the reactivation of the Hill reaction in $\mathrm{CO}_{2}$-depleted chloroplasts by addition of bicarbonate in the absence and in the presence of herbicides. Physiol Plant 57:422-427 
Snel JFH, van Rensen JJS (1984) Reevaluation of the role of bicarbonate and formate in the regulation of photosynthetic electron flow in broken chloroplasts. Plant Physiol 75:146-150

Stemler A (1980) Inhibition of photosystem II by formate: possible evidence for a direct role of bicarbonate in photosynthetic oxygen evolution. BBA-Bioenerg 593:103-112

Stemler A (1986) Carbonic anhydrase associated with thylakoids and photosystem II particles from maize. BBA-Bioenerg 850(1):97-107

Stemler AJ (1997) The case for chloroplast thylakoid carbonic anhydrase. Physiol Plant 99(2):348-353

Stemler AJ (2002) The bicarbonate effect, oxygen evolution and the shadow of Otto Warburg. Photosynth Res 73:177-183

Stemler A, Murphy J (1983) Determination of the binding constant of $\mathrm{H}^{14} \mathrm{CO}_{3}{ }^{-}$to the photosystem II complex in maize chloroplasts: effects of inhibitors and light. Photochem Photobiol 38:701-707

Stemler A, Radmer R (1975) Source of photosynthetic oxygen in bicarbonate-stimulated Hill reaction. Science 190(4213): $457-458$

StemlerGovindjee A (1973) Bicarbonate ion as a critical factor in photosynthetic oxygen evolution. Plant Physiol 52:119-123

StemlerGovindjee A (1974) Effects of bicarbonate ion on chlorophyll a fluorescence transients and delayed light emission from maize chloroplasts. Photochem Photobiol 19:227-232

Tikhonov K, Shevela D, Klimov VV, Messinger J (2018) Quantification of bound bicarbonate in photosystem II. Photosynthetica 56(1):210-216

Tripathy BC, Mohanty P (1980) Zinc-inhibited electron transport of photosynthesis in isolated barley chloroplasts. Plant Physiol 66(6): 1174-1178

Ulas G, Olack G, Brudvig GW (2008) Evidence against bicarbonate bound in the $\mathrm{O}_{2}$-evolving complex of photosystem II. Biochemistry $47(10): 3073-3075$
Umena Y, Kawakami K, Shen JR, Kamiya N (2011) Crystal structure of oxygen-evolving photosystem II at a resolution of $1.9 \AA$. Nature 473(7345):55-60

Van Rensen JJS (2002) Role of bicarbonate at the acceptor side of photosystem II. Photosynth Res 73(1-3):185-192

Van Rensen JJS, XuGovindjee C (1999) Role of bicarbonate in photosystem II, the water-plastoquinone oxido-reductase of plant photosynthesis. Physiol Plant 105(3):585-592

van Rensen JJS, Vermaas WFJ (1981) Action of bicarbonate and photosystem II inhibiting herbicides on electron transport in pea grana and in thylakoids of a blue-green alga. Physiol Plant $51: 106-110$

Villarejo A, Shutova TV, Moskvin O, Forssen M, Klimov VV, Samuelsson G (2002) A photosystem II-associated carbonic anhydrase regulates the efficiency of photosynthetic oxygen evolution. EMBO J 21(8):1930-1938

Warburg O, Krippahl G (1958) Hill-Reaktionen. Z Naturforsch 13:509-514

Warburg O, Krippahl G, Jetschmann C (1965) Widerlegung der photolyse des wassers und beweis der photolyse der kohlensäure nach versuchen mit lebender Chlorella und den hill-reagentien nitrat und $\mathrm{K}_{3} \mathrm{Fe}(\mathrm{CN})_{6}$. Z Naturforsch B 20(10):993-996

Wei X, Su X, Cao P, Liu X, Chang W, Li M, Zhang X, Liu Z (2016) Structure of spinach photosystem II-LHCII supercomplex at 3.2 $\AA$ resolution. Nature 534(7605):69-74

Wu YY, Li HT, Xie TX (2015) The regulation on carbon source and carbon sequestration by microalgal carbonic anhydrase. Biogeochemical action of microalgal carbonic anhydrase. Science Press, Beijing, pp 76-111

Wydrzynski T, Govindjee (1975) A new site of bicarbonate effect in photosystem II on photosynthesis: evidence from chlorophyll fluorescence transitions in spinach chloroplasts. BBA - Bioenerg 387:403-408 